\title{
Os livros didáticos Domani e Magari em contexto ítalo-brasileiro
}

\author{
Los manuales Domani y Magari en contexto ítalo-brasileño \\ Textbooks Domani and Magari in an Italian-Brazilian context
}

\author{
Me. Wânia Cristiane Beloni ${ }^{1}$
}

\begin{abstract}
Resumo
Trabalhar com aspectos culturais em sala de aula é uma forma de aquisição de uma segunda cultura, de desenvolvimento e conhecimento intercultural. É preciso compreender os fatores históricos, geográficos e sociais, os quais, consequentemente, delineiam as variedades linguísticas e a cultura de uma comunidade. É necessário, ainda, entender como se configura o comportamento em relação à variedade minoritária italiana e à cultura desses grupos, assim como as diferenças históricas, linguísticas da língua italiana como língua estrangeira (língua padrão) e as variedades linguísticas italianas distintas, daquela ensinada na escola como língua oficial. Para que o professor contemple e respeite os aspectos culturais em sala de aula e desenvolva a formação intercultural do estudante, de uma forma crítica e reflexiva, ele precisa ir além das limitações do livro didático, o qual tem caráter amplo e por isso não considera todas as especificidades de um determinado contexto. Nesse sentido, será apresentada uma análise dos livros didáticos de italiano como língua estrangeira Domani e Magari, ambos da Alma Edizioni, utilizados para o ensino formal em Cascavel/PR, assim como aspectos socioculturais, históricos e linguísticos da comunidade. Para isso, a Linguística Aplicada será relacionada à Sociolinguística, a estudos culturais e históricos.
\end{abstract}

Palavras-chave: Ensino intercultural, Material didático, Variação linguística

\section{Resumen}

Trabajar aspectos culturales en el aula es un modo de adquisición de una segunda cultura, de desarrollo y conocimiento intercultural. Es necesario comprender las causas históricas, geográficas y sociales, las cuales, en consecuencia, dibujan las variedades lingüísticas y la cultura de una comunidad. También es necesario entender cómo se configura el comportamiento en relación a la variedad minoritaria italiana y a la cultura de esos grupos, así como las diferencias históricas y lingüísticas de la lengua italiana como lengua extranjera (lengua estándar) y las variedades lingüísticas italianas distintas de aquella enseñada en la escuela como lengua oficial. Para que el profesor comprenda y respete los aspectos culturales en el aula y desarrolle la formación intelectual del estudiante, de modo crítico y reflexivo, él necessita transponer las limitaciones de los manuales de enseñanza, los cuales tienen carácter amplio y, por tanto, no consideran los rasgos específicos de un contexto dado. En este sentido, se presentará un análisis de los manuales de italiano como lengua extranjera Domani y Magari, los dos de Alma Edizioni, utilizados para la enseñanza formal en Cascavel/PR, así como aspectos socioculturales, históricos y lingüísticos de la comunidad. Para ello, la Lingüística Aplicada será relacionada a la Sociolingüística, a los estudios culturales y históricos.

Palabras claves: Enseñanza intercultural, Material didáctico, Variación lingüística

\begin{abstract}
Working with cultural aspects in the classroom is a way of acquiring a second culture, intercultural development and knowledge. There is the need to understand historical, geographical and social factors, which consequently outline the linguistic varieties and culture of a community. There is also the need to understand how behavior is built up in relation to the variety of Italian minorities and the culture of these groups, as well as the historical,
\end{abstract}

\footnotetext{
${ }^{1}$ Mestre e doutoranda em Letras, sob orientação de Clarice Nadir von Borstel; Universidade Estadual do Oeste do Paraná - Unioeste; Cascavel, Paraná, Brasil; wania.beloni@ hotmail.com
} 
linguistic differences of the Italian language as a foreign language (standard language) and the different Italian linguistic varieties from what is taught in school as the official language. To contemplate and respect the cultural aspects in the classroom and develop the intercultural formation of students, in a critical and reflective manner, teachers must go beyond the limitations of a textbook, which has a comprehensive nature and therefore does not consider all the specificities of a given context. In this sense, we will present an analysis of the Italian textbooks as a foreign language Domani and Magari, both from publishing house Alma Edizioni, used in formal education in the city of Cascavel, Paraná State, as well as the sociocultural, historical and linguistic aspects of its community. To this end, Applied Linguistics will be associated with Sociolinguistics, cultural and historical studies.

Key-words: Intercultural learning, Teaching material, Linguistic variation

\section{Introdução}

Em Cascavel, no Oeste do Paraná, há muitos descendentes de italianos e por isso, o professor de língua italiana padrão precisa considerar a história de muitos alunos e lembrar que os antepassados de muitos desses estudantes vieram da Itália, se estabeleceram no Sul do Brasil e na região Sudeste do país, deslocaram-se para Cascavel, trazendo com eles a língua italiana dialetal e a cultura da região de origem europeia e brasileira.

Segundo Luzzatto (2005), dos aproximadamente 100 mil imigrantes que vieram para o Brasil, “[...] 54\% são vênetos, 33\% são lombardos, 7\% são trentinos, 4,5\% são friulanos e 1,5\% são de outras regiões, incluindo os trivênetos, teríamos: $65,5 \%$ de trivênetos, $33 \%$ lombardos e 1,5\% de outras regiões da Itália" (LUZZATTO, 2005, p. 15). Sendo assim, a maioria dos imigrantes eram trivênetos e por isso foi este dialeto que acabou permanecendo e vigorando nas colônias do sul do país. Esta forma de falar do Sul do Brasil acabou sofrendo influências do contexto em que estava inserido e por isso, acabou se transformando, sendo chamado de $\operatorname{talian}^{2}$ por Luzzatto (2000), ou vêneto brasileiro, o qual está presente ainda hoje, na fala e na memória não apenas de gaúchos e catarinenses, mas também de muitos descendentes que se deslocaram e chegaram ao oeste paranaense.

Segundo os dados do Instituto Brasileiro de Geografia e Estatística (IBGE) de 2010, das 286.205 pessoas residentes em Cascavel, a maioria, sendo mais de 259 mil, nasceu na região Sul do Brasil. Os dados de 2010 reafirmam os dados de 1970, apresentados e considerados por Piaia (2013), registrando que a maioria da população em Cascavel era

\footnotetext{
${ }^{2}$ A maioria dos imigrantes italianos, ao chegarem ao Brasil no século XIX, era monolíngue, falava o dialeto de sua região italiana de origem - Veneto, Lombardia, Trentino Alto Ádige e Friuli Venezia Giulia - do Norte da Itália. Como quase $60 \%$ dos imigrantes italianos eram do Vêneto, foi o dialeto desta região que prevaleceu entre eles. Surge, então, nas colônias do Rio Grande do Sul, uma nova variação linguística que teve no início função de koiné, ou seja, de comunicação entre famílias italianas que tinham variáveis distintas ao se comunicarem. Com base no dialeto vêneto, as famílias italianas, em um novo contexto, em que se falava português, quando se tornaram bilíngues, acabaram transformando o dialeto vêneto. Este sofreu influências do português e, assim, transformou em um novo modo de falar, chamado de talian, ou de vêneto brasileiro, o qual está presente, também, no Oeste do Paraná.
} 
proveniente dos estados do Paraná, Rio Grande do Sul e Santa Catarina. Desde aquela época, porém, a cidade já contava com a presença de brasileiros de outros estados como São Paulo e Minas Gerais, ainda que em número menor.

Compreender a realidade linguística que nos cerca é um desafio para qualquer indivíduo, e que precisa, a partir de suas experiências, romper com pré-conceitos e estigmas quanto à cultura e à forma de falar do outro. Nesse sentido, as perspectivas sociolinguísticas e interacionais podem auxiliar no ensino-aprendizagem de uma língua.

Pensando nessa situação de ensino, escolher um material didático de italiano como língua estrangeira é um desafio para o professor que se encontra em um contexto de colonização italiana. Ensinar a língua padrão, sem desconsiderar o cenário cultural e linguístico em que os alunos se encontram, trabalhando aspectos culturais em sala de aula é uma maneira de formar não apenas falantes competentes linguisticamente, mas é um dever social contribuir com o desenvolvimento e o conhecimento intercultural dos estudantes.

Rojo (2013) observa que o professor competente ou eficiente é aquele que vai além das limitações do livro didático, o qual tem caráter genérico e por isso não pode contemplar todas as especificidades de um determinado contexto. Sendo assim, deve-se complementar, ajustar e/ou aprofundar determinado conteúdo ou tema abordado no material didático, assim como apresentar e relacionar assuntos que o manual não contemple, mas que sejam necessários para o desenvolvimento do conhecimento e da formação intercultural do estudante, de uma forma crítica e reflexiva.

Nesse sentido, será apresentada uma breve análise de livros didáticos de italiano como língua estrangeira utilizados para o ensino formal em Cascavel/PR, considerando alguns aspectos socioculturais, históricos e linguísticos da comunidade. Dessa forma, existe a necessidade de integrar a Linguística Aplicada à Sociolinguística, a estudos culturais e históricos para que não ocorra um apagamento da pluralidade linguística e cultural de um grupo em favor de uma língua oficial e de uma cultura em relação à outra.

\section{O ensino de língua estrangeira}

A linguagem é fundamental para a interação humana, para a vida em sociedade. Saussure, no final do século XIX e início do século XX, apesar de não se ater à fala em sua constituição heterogênea, contribuiu para que a linguística se tornasse oficialmente uma ciência, tendo como objeto de estudo a língua. Em meados do século XX, surgiu a 
preocupação com a prática, com a aplicação desse conhecimento por meio de situações reais de uso linguístico, com o ensino de línguas.

A Segunda Guerra Mundial, entre 1939 e 1945, fez com que surgisse a necessidade de comunicação entre falantes de diferentes línguas, aliados ou não de guerra. Com isso, os métodos de ensino e aprendizagem de língua estrangeira, com base na abordagem Gramática e Tradução, acabaram sendo questionados, uma vez que se pautavam essencialmente no desenvolvimento da leitura com base em regras gramaticais e na tradução de listas de palavras.

A partir desse cenário, com base na psicologia behaviorista, o ensino e a aprendizagem de línguas estrangeiras se fundamentaram, nessa época, aproximadamente em 1940, no método audiolingual, o qual tem como fundamento ações de estímulo-resposta por meio, por exemplo, de atividades de memorização de diálogos e exercícios de repetição, em que o ensino da gramática era indutivo.

No fim da década de 1950, a teoria Linguística gerativo-transformacional de Chomsky, tendo como foco a linguagem em uso, coexistiu com a Linguística Aplicada (LA), o que gerou certa resistência, uma vez que o objeto de estudo da linguística, apresentado por Saussure, não teria foco na fala e consequentemente desconsiderava o contexto de uso, os quais revelam aspectos culturais, históricos e sociais.

Foi apenas nas últimas décadas do século XX que pesquisas da Sociolinguística assim como de teorias de texto e de discurso contribuíram para que se focalizasse a linguagem em uso e as implicações enunciativas e intencionais. Nesse sentido, a LA, que no início se estabeleceu apenas com o ensino de línguas com base em aspectos gramaticais, de repetição e instrumentais, com o tempo se ampliou, focalizando o uso da língua em diferentes contextos e interações.

Nesse contexto, a Abordagem Comunicativa, método de ensino desenvolvido na Europa desde os anos de 1970 que se pauta no cognitivismo, deixou de trabalhar a língua como apenas um código linguístico e passou a considerá-la como instrumento de comunicação e de interação social. Assim, nessa perspectiva, o aluno se tornaria mais competente na comunicação.

A Abordagem Comunicativa foi um grande passo para o desenvolvimento do ensino de línguas. Nesse processo, o professor deixa de ser o centro e passa à condição de mediador do processo pedagógico, o erro passa a fazer parte do processo de ensino e aprendizagem, um estágio provisório de interlíngua. Apesar disso, na década de 1990, essa abordagem começou a ser criticada, pois, "Nessa abordagem, o conceito de cultura configura uma visão 
homogênea que a percebe dissociada da língua, muitas vezes abordados de forma estereotipada" (PARANÁ, 2008, p. 51). Segundo os documentos oficiais, portanto:

Tais questões marginalizam razões históricas e/ou étnicas que podem ser valorizadas, levando-se em conta a história da comunidade atendida pela escola. Destaca-se que o comprometimento com o plurilinguismo como política educacional é uma das possibilidades de valorização e respeito à diversidade cultural, garantido na legislação, pois permite às comunidades escolares a definição da Língua Estrangeira a ser ensinada (PARANÁ, 2008, p. 52).

Mesmo assim, apesar de as diretrizes notarem a importância de se trabalhar com gêneros e aspectos culturais/interdiscurso, ao citar a variedade linguística o documento evidencia apenas a questão de registro formal e informal, não especificando e citando as variações linguísticas presentes em diferentes regiões.

Os Parâmetros Curriculares Nacionais (PCNs), por outro lado, destacam no subitem Variação linguística - a existência de formas de falar distintas, assim como o preconceito que falantes de formas linguísticas diferentes da norma padrão enfrentam. No item Pluralidade cultural, são evidenciados, também, as variações: "Não faz sentido, por exemplo, considerar o espanhol somente como a língua da Espanha, como também considerar o inglês somente como a língua da Inglaterra ou dos Estados Unidos, ou o francês como a língua da França" (BRASIL, 1998, p. 47).

Nesse sentido, os PCNs se calcam na concepção teórica fundamentada em Mikhail Bakhtin, em que a contextualização sócio-histórica deve ser levada em conta para que se compreenda uma linguagem, a qual se constrói por meio da comunicação verbal entre sujeitos históricos.

A concepção de língua, com base nos estudos do Círculo de Bakhtin, considera a linguagem como um fenômeno social, calcado em relações sociais, em que a língua não é construída de forma monológica isolada e nem por um sistema abstrato de formas linguísticas: "mas pelo fenômeno social da interação verbal, realizada através da enunciação ou das enunciações. A interação verbal constitui assim a realidade fundamental da língua" (BAKHTIN/VOLOCHINOV, 1992, p. 123).

Dessa forma, o conhecimento é construído com base na interlocução e na participação ativa dos sujeitos que interagem. Com base nos pensamentos de Bakhtin (2003), é preciso considerar o interlocutor como um sujeito social, histórico e ideologicamente situado. Além disso, o pensador evidencia a importância da relação com o outro, ou seja, da alteridade para a construção da identidade do indivíduo: "Porque em qualquer situação ou proximidade que 
esse outro que eu contemplo possa estar em relação a mim, sempre saberei e verei algo que ele, da sua posição fora e diante de mim, não pode ver" (BAKHTIN, 2003, p. 21). Sendo assim, ao se relacionar, a identidade do sujeito está em constante processo de construção e de autoconhecimento.

Nesse sentido, faz-se necessário promover a interação e a aproximação com o outro, com base em uma relação de respeito e reflexão. O ensino intercultural proporciona, além da proficiência, a consciência crítica do aluno que ao se deparar com as diferenças linguísticas e culturais dos colegas, estará se construindo e refletindo sobre a própria cultura, instrumentalizando-se e humanizando-se ao mesmo tempo.

O ensino transversal de línguas, pela vertente INdisciplinar (MOITA LOPES, 2006) e transgressiva (PENNYCOOK, 2006) da Linguística Aplicada considera que os estudos de diversas áreas podem possibilitar uma melhor aprendizagem de uma língua, pois pelo viés da interdisciplinaridade, a LA mestiça ou nômade, faz com que se repense o ensino de língua a partir do contexto aplicado, "onde as pessoas vivem e agem” (MOITA LOPEZ, 2006, p. 21), proporcionando um letramento crítico. Sendo assim, foi o viés da interdisciplinaridade que possibilitou mais desenvolvimento à LA contemporânea, a qual está, ainda, no entanto, se desenvolvendo com o apoio de diversas outras áreas. Pensar no ensino de língua, na LA, em um contexto aplicado, em que as pessoas vivem, agem e interagem socioculturalmente, é o desafio da prática de ensino eficiente.

Ao ensinar uma língua, seja estrangeira seja materna, é necessário levar em conta o conhecimento de mundo que os estudantes têm. Nesse sentido, os PCNs enfatizam que "um dos processos centrais de construir conhecimento é baseado no conhecimento que o aluno já tem: a projeção dos conhecimentos que já possui no conhecimento novo, na tentativa de se aproximar do que vai aprender" (BRASIL, 1998, p. 32).

Para Pichiassi (1999), a glotodidática associa a língua e a cultura, sendo esta, indispensável para que se aprenda um idioma de fato, até porque "la lingua è veicolo e allo stesso tempo manifestazione di cultura, per cui l'acquisizione di una lingua comporta l'assimilazione anche dei tratti culturali propri della società che usa quella lingua" (PICHIASSI, 1999, p. 23) . $^{3}$

Dessa forma, para aprender uma língua é necessário aprender também as formas de expressões dessa língua, que se manifestam por meio da cultura. Sobre isso, Gimenez e

\footnotetext{
${ }^{3}$ a língua é veículo e ao mesmo tempo manifestação de cultura, por isso a aquisição de uma língua comporta a assimilação inclusive de comportamentos/aspectos culturais próprios da sociedade que utiliza aquela língua (PICHIASSI, 1999, p. 23, tradução nossa).
} 
Furtoso (2002, p. 51) também comentam, ao dizerem que o professor de língua estrangeira precisa conhecer outras culturas, pois "não é possível ensinar uma língua estrangeira desvinculada dos aspectos socioculturais e históricos que as constroem”.

Partindo de uma postura calcada na LA contemporânea e na abordagem intercultural, sem deixar de lado as abordagens comunicativa e sociointeracional, ou seja, a partir do pósmétodo, o professor precisa oportunizar trocas de conhecimentos culturais e linguísticos em sala de aula para que o aluno desenvolva uma leitura crítica sobre o país em que está vivendo, assim como sobre sua própria cultura, sobre seu próprio comportamento, crenças e valores. Mello, Santos e Almeida (2002, p. 96) falam sobre a importância de o professor desenvolver "não só a competência linguística de seus alunos, mas também a competência sociolingüística”, e que assim, por sua vez, o estudante saberá adequar o sistema linguístico à função do contexto social.

De acordo com Calvet (2002), a relação da língua com a cultura é indissolúvel, pois aquela é uma das formas de representação da cultura de um povo e esta se materializa em um ou mais idiomas, pois uma cultura pode ser descrita por meio de uma diversidade de palavras, as quais têm como objetivo atender uma determinada necessidade, um fenômeno específico. Nesse sentido, fatores geográficos, históricos e sociais contribuem para a formação de uma cultura e de uma língua, pois uma é reflexo da outra.

Celentin e Serragiotto (2000) observam que a língua não é apenas um instrumento abstrato de regras e construções sintáticas, mas é resultado de uma cultura específica, a qual se manifesta por meio da linguagem e que "L'acquisizione di una seconda lingua implica l'acquisizione di una seconda cultura" (CELENTIN; SERRAGIOTTO, 2000, p. 5) ${ }^{4}$. Pela perspectiva do ensino intercultural, segundo os autores, o aluno aprenderá não apenas a língua, mas desenvolverá uma consciência de respeito às diferenças, pois conhecerá outras culturas e terá a oportunidade de aprender a não estereotipar, pois "Secondo questo principio, non esiste una cultura migliore di un'altra, ma ognuna rappresenta in modo completo un popolo" (CELENTIN; SERRAGIOTTO, 2000, 10) ${ }^{5}$, a qual se manifesta nos mais variados aspectos da vida cotidiana: na gastronomia, na arquitetura, na concepção de tempo e espaço, no comportamento.

Para se propor um ensino pelo viés intercultural não é preciso que o contexto seja multicultural. No entanto, dificilmente há espaços urbanos sem conflitos, sem a presença de

\footnotetext{
4 "A aquisição de uma segunda língua implica na aquisição de uma segunda cultura" (CELENTIN; SERRAGIOTTO, 2000, p. 5, tradução nossa).

5 "Segundo esse princípio, não existe uma cultura melhor do que outra, mas cada uma representa um povo de modo completo" (CELENTIN; SERRAGIOTTO, 2000, 10, tradução nossa).
} 
culturas diferentes. Nesse sentido, a interculturalidade pode, talvez, ser sempre útil para promover melhores convivências.

A perspectiva intercultural pode ser, portanto, uma forma de contribuir, pois, assim como Mezzadri observa, "la competenza comunicativa interculturale non può essere insegnata; il docente di lingua straniera può solo insegnare a osservarla" (MEZZADRI, 2003, p. 239) ${ }^{6}$. Nesse sentido, o ensino de língua estrangeira pode ir além do objetivo de formar um falante competente. Pode ser uma maneira de contribuir com a formação crítica, com a formação humana de outros cidadãos.

\section{3. $O$ viés metodológico da pesquisa}

Realizamos, neste trabalho, uma breve análise dos livros didáticos de língua italiana para estrangeiros Domani (níveis A1, A2 e B1) e Magari (B1, B2 e C1), ambos da Alma Edizioni. A seleção dos materiais se deve ao fato de as duas publicações fazerem parte da documentação escolar do curso de Letras Português/Italiano da Universidade Estadual do Oeste do Paraná (Unioeste), Campus de Cascavel.

Pessanha, Daniel e Menegazzo (2004, p. 63) explicam que para observar a cultura escolar como objeto histórico deve-se considerar e analisar os saberes e valores impostos no espaço escolar. Para isso, os autores notam que é necessário analisar o conjunto de normas e práticas escolares, os comportamentos, e que muitas vezes isso pode ser observado em "cadernos, planos de ensino, livros, provas e material didático geral”. Para os autores, as fontes primárias são "o elemento mais importante para esclarecer lacunas de documentos, de memória, ou mesmo para alterar estereótipos cristalizados e reproduzidos ad aeternum através da utilização apenas de fontes secundárias", ou seja, nem sempre o que está nos documentos oficiais (nacionais, estaduais e até mesmo nos planos de ensino) é o que acontece de fato em sala de aula.

Para Gil (2002, p. 47), as pesquisas elaboradas com base em documentos "são importantes não porque respondem definitivamente a um problema, mas porque proporcionam melhor visão desse problema ou, então, hipóteses que conduzem a sua verificação por outros meios".

Nesse sentido, para Gil (2002), as vantagens da pesquisa documental são: fonte rica e estável de dados; a subsistência ao longo do tempo; a natureza histórica; o baixo custo; a não

\footnotetext{
6 “a competência comunicativa intercultural não pode ser ensinada; o docente de língua estrangeira pode apenas ensinar os estudantes a observá-la” (MEZZADRI, 2003, p. 239).
} 
necessidade de contato com os sujeitos da pesquisa. No entanto, a principal limitação seria a não-representatividade e a subjetividade dos documentos. Assim, partir para uma pesquisa in loco torna-se fundamental para diagnosticar outras questões a serem consideradas, como o contexto histórico de Cascavel e de seus habitantes.

Sendo assim, esta pesquisa se inscreve na perspectiva teórica da Linguística Aplicada, articulada aos estudos variacionistas. A pesquisa qualitativa nas ciências sociais "procura entender, interpretar fenômenos sociais inseridos em um contexto" (BORTONI-RICARDO, 2008, p. 34), rebatendo as pesquisas com base em Comte, que negligenciavam o contexto histórico-social em que os fenômenos estudados estavam inseridos.

A análise foi feita para avaliar principalmente dois aspectos: (1) se o material propõe uma abordagem intercultural; (2) se o material considera e/ou apresenta reflexões sobre as variedades linguísticas italianas. Avaliando esses dois aspectos, pretende-se observar se os materiais possibilitam o desenvolvimento da competência sociolinguística.

Após uma breve análise dos manuais didáticos, sistematizamos os resultados com o objetivo de identificar se há propostas de trabalho com variações linguísticas do italiano e com aspectos interculturais. Dessa forma, foi possível refletir sobre a necessidade de adequação de material de ensino aprendizagem para o contexto escolar dos cascavelenses e sugerir as relações pertinentes para aperfeiçoar o trabalho em sala de aula.

\section{Análise dos livros Domani e Magari}

Ambos os livros - Domani e Magari - são produções da editora Alma, da cidade de Florença (Itália), para o ensino de italiano para estrangeiros adultos. Nesse sentido, as obras didáticas não são destinadas a um país e etnia específicos. Sendo assim, eles não poderiam atender as necessidades de um grupo, no caso, do Oeste do Paraná. No entanto, pensando nesse contexto específico, pretende-se analisar esses livros para observar a abordagem intercultural e se existe algum enfoque sobre as variedades linguísticas em algum momento ou se há uma forma de encontrar um ponto em que o professor de italiano possa, a partir dessa prática, relacionar com o contexto sociocultural e linguístico dos alunos.

As três obras em análise da série Domani (1, 2 e 3$)$ foram publicadas pela primeira vez nos anos de 2010, 2011 e 2012, respectivamente. Já o livro Magari (B1, B2 e C1) foi lançado em $2008^{7}$. Produzidos para níveis diferentes, as duas séries apresentam a mesma perspectiva

\footnotetext{
${ }^{7}$ Mais recentemente a editora Alma colocou no mercado o Nuovo Magari, dividido em dois livros (B2 e C1/C2). A obra mais recente não será aqui analisada por ainda não fazer parte da documentação escolar do curso de
} 
de ensino, com base na abordagem global, centrado na textualidade (nos gêneros), na aprendizagem indutiva, no estudante como centro, protagonista ativo e no aspecto cooperativo com base nas teorias de Vygotskij.

A série Domani, voltada para estudantes estrangeiros, adultos e adolescentes, que aprendem o italiano como língua estrangeira ou segunda língua, se caracteriza, ainda, pelo aprendizado por meio de jogos e pelo trabalho com a "multissensorialidade (auditiva, visual, dinâmico-espacial, etc.)", assim como pelo "forte valor cultural", "dando atenção às modalidades expressivas, relacionais, sociais do ser italiano, mas também às tendências, às ideias, aos estilos de vida emergentes além dos estereótipos, banalizações e simplificações" (GUASTALLA; NADDEO, 2010b, p. 5, tradução nossa) ${ }^{8}$, ou seja, percebe-se que o livro se anuncia cultural.

Os livros dessa coletânea se organizam em cinco áreas temáticas - geografia, arte, sociedade, história e língua -, sendo que no primeiro volume, as unidades contemplam apenas os três primeiros temas. Assim como no Domani, no Magari as unidades também são trabalhadas sobre essas cinco temáticas e considera o Quadro Comune Europeo di Riferimento (QCER) ${ }^{9}$. Nesse sentido, percebe-se que o trabalho com a abordagem chamada global, pelo livro, tem como intuito englobar diversos aspectos linguísticos e sociolinguísticos, tendo como objetivo o trabalho com a competência linguística, pois estudar a língua significa "não aprender apenas as regras morfológicas e sintáticas, mas enfrentar também o conjunto de aspectos que cada vez entram em jogo quando se trata de comunicação (aspectos pragmáticos, conversacionais, lexicais, socioculturais, interculturais [...]" (GUASTALLA; NADDEO, 2010b, p.12, tradução nossa). ${ }^{10}$

Nesse sentido, percebe-se, pelos discursos apresentados no guia do professor, que a obra se caracteriza pelo pós-método e que a questão cultural é almejada. No índice dos materiais, cada unidade é apresentada com um tema, sendo evidenciadas as seguintes categorias: comunicação, gramática, léxico, textos escritos e orais, cultura.

Letras Italiano da Unioeste. No entanto, esta apresenta apenas três unidades diferentes, no nível B2. Percebe-se, também, que houve a mudança na classificação dos níveis trabalhados na obra, a qual continua sendo praticamente a mesma.

8 "ponendo l'accento sulle modalità espressive, relazionali, sociali dell'essere italiani nonché sulle tendenze, le idee, gli stili di vita emergenti al di là di stereotipi, banalizzazioni e semplificazioni" (GUASTALLA; NADDEO, 2010b, p. 5).

${ }^{9}$ O QCER foi elaborado pelo Consiglio d'Europa em 1996, publicado em inglês e francês em 2001 e em italiano em 2002 (La Nuova Italia).

${ }^{10}$ Domani privilegia un approccio globale alla lingua. In questa visione, studiare la lingua significa non solo apprendere le regole morfologiche e sintattiche, ma affrontare anche l'insieme degli aspetti che ogni volta entrano in gioco quando si tratta di comunicazione (aspetti pragmatici, conversazionali, lessicali, socioculturali, interculturali... (GUASTALLA; NADDEO, 2010b, p.12). 
No Domani 1, diversos assuntos relacionados à cultura são apresentados, tais como: modos de cumprimentar-se, nomes próprios mais difundidos; cidades italianas; ecologia; cidades da arte, Caravaggio; pintura italiana; filmes italianos; pão, pizza e outros, tomar um café, expressões; a família italiana; geografia da Itália; o turismo da arte; música italiana; o tempo livre; espetáculos ao vivo, Roberto Benigni, A Divina Comédia. No entanto, em relação a questões socioculturais e interculturais, a obra pouco se aprofunda nesse sentido. $\mathrm{Na}$ quarta unidade, por exemplo, com o tema "Uma noite em Roma", são apresentados os adjetivos de nacionalidade, na página 37, a partir de um áudio, porém, não se trabalha o viés intercultural, o intercâmbio de culturas.

Na unidade 11, os autores apresentam algumas variações lexicais entre mamma e papà (mamãe e papai): “Os filhos chamam a mãe de mamma e o pai de papà (ou babbo em algumas áreas da Itália central, sobretudo na Toscana)" (GUASTALLA; NADDEO, 2010a, p. 89, tradução nossa) ${ }^{11}$, entre outras questões, o que demonstra um acanhado trabalho com as variações linguísticas.

Na última unidade do primeiro volume do Domani, os autores trabalham com uma notícia sobre a interpretação de Roberto Benigni de Dante Alighieri e apresentam um pequeno quadro com algumas informações sobre a Divina Comédia. Todavia, mais uma vez, fica a cargo do professor relacionar a obra com as variações linguísticas, no caso, históricas.

No Domani 2, diversos temas culturais são trabalhados, entre eles: o sistema de instrução na Itália; boas maneiras em dar e receber presentes, parabenizar, o casamento da Itália; festas e tradições italianas; pratos típicos, as refeições na Itália, regras de comportamento no restaurante; etc.

A primeira unidade do segundo volume, intitulada "W gli sposi" (Vivam os noivos), chama atenção pelo tratamento intercultural. A unidade inicia com as ocasiões (aniversário, casamento, convite para janta, formatura, nascimento de um bebê, Natal) e com presentes que podem ser associados. Logo abaixo segue a pergunta 1b: "E no teu País, o que se presenteia nessas ocasiões? Há diferenças em relação à Itália? Converse sobre isso com um colega" (GUASTALLA; NADDEO, 2011a, p. 16, tradução nossa). ${ }^{12}$ Nesse sentido, o Domani 2 tem um direcionamento intercultural, com finalidades e objetivos nessa perspectiva, assim como Celentin e Serragiotto (2000) observam sobre o diálogo, o qual tem como intuito promover “mais sensibilização em relação aos problemas ligados às relações interculturais e uma

\footnotetext{
11 "I figli chiamano la madre mamma e il padre papà (o babbo in alcune zone dell'Italia centrale, soprattutto in Toscana)" (GUASTALLA; NADDEO, 2010a, p. 89).

12 "E nel tuo Paese cosa si regala in queste occasioni? Ci sono differenze con l'Italia? Parlane con un compagno" (GUASTALLA; NADDEO, 2011a, p. 16).
} 
formação à tolerância às diversidades; criar um clima de diálogo e de abertura, que leve à comparação/relação e ao enriquecimento recíproco" (CELENTIN; SERRAGIOTTO, 2000, p. 22 , tradução nossa). ${ }^{13}$

Celentin e Serragiotto (2000, p. 16) evidenciam diversas situações de confronto em que um estrangeiro pode se deparar quando entra em contato e se comunica com um italiano, tais como: o volume e o tom de voz (eles adotam um tom de voz notavelmente superior em relação a outros povos e às vezes parecem estar brigando mesmo que não estejam); a velocidade da elocução; a postura (entender em quais situações é necessário assumir uma postura mais formal e em outras situações são mais informais); os gestos; pontualidade (os italianos toleram um atraso de quinze minutos; ou melhor, dentro desse espaço de tempo eles nem mesmo consideram um atraso); dialetos; interrupção (para um italiano é normal, durante uma conversação, um debate, uma mesa redonda, interromper a pessoa que está falando, às vezes apenas para demonstrar concordância com aquilo que está sendo afirmado); entre outras questões.

Nesse sentido, ao lado do exercício $1 \mathrm{~b}$ (observado anteriormente), na mesma página 16, os autores apresentam um quadro com o título Cosa NON fare in Italia (O que não fazer na Itália), e as seguintes explicações: "Na Itália você é mal educado se... não abrir subitamente um presente que recebeu; não dizer que o presente que você recebeu é lindíssimo (mesmo que não seja verdade); presentear uma carteira vazia; não levar nada quando for convidado para uma janta (ou levar um vinho de má qualidade)" (GUASTALLA; NADDEO, 2011a, p. 16, tradução nossa). Entretanto, nesse momento não se propõe a reflexão sobre esses comportamentos no país do aluno estrangeiro. Na sequência, todavia, na página 17, o próximo exercício, 2, inicia com a seguinte questão: “Come si svolge un matrimonio nel tuo Paese? Quali sono le abitudini e le tradizioni?" (Como é feito um casamento no teu País? Quais são os hábitos e as tradições?), o que demonstra, mais uma vez, alguns aspectos da abordagem intercultural.

No Domani 2, diversos temas culturais chamam atenção, como Festas e tradições, na unidade 2, o qual, todavia, não se reflete a questão intercultural, colocando como centro a cultura italiana, assim como em diversos outros momentos.

\footnotetext{
13 "In realtà, quello si vuole promuovere, è una maggiore sensibilizzazione ai problemi legati ai rapporti interculturali e una formazione alla tolleranza delle diversità; creare un clima di dialogo e di apertura, che porti al confronto e all'arricchimento reciproco" (CELENTIN; SERRAGIOTTO, 2000, p. 22).
} 
Na página 60, os autores apresentam alguns pontos de variação gastronômica, que se refletem, consequentemente, em variação linguística, em um pequeno quadro, intitulado $L a$ cucina italiana (A cozinha italiana):

\begin{abstract}
Na Itália não há uma única cozinha nacional, mas há diversas cozinhas, das regiões e das cidades, com pratos típicos muito famosos. Alguns pratos populares: as trofie al pesto em Gênova, o risoto em Milão, os tortellini em Bolonha, a ribollita em Florença, o espaguete à carbonara em Roma, o orecchiette em Apúlia, o macarrão à Norma na Sicília, o porquinho em Sardenha (GUASTALLA; NADDEO, 2011a, p.60, tradução nossa). ${ }^{14}$
\end{abstract}

Alguns termos como trofie (um tipo de macarrão) e ribollita (uma sopa toscana de feijão branco) são alguns pontos em que o professor de italiano pode desenvolver o trabalho com as variações linguísticas, apesar de isso não ser indicado na obra.

$\mathrm{Na}$ unidade 13, Guastalla e Naddeo (2011a) apresentam um texto no segundo exercício, na página 110, em que duas amigas trocam e-mails e uma delas, com um namorado estrangeiro, passa uma situação difícil, devido à falta de entendimento do namorado com o garçom de uma pizzaria italiana, devido a um gesto não interpretado corretamente. O texto é engraçado e trabalha a diversidade comunicativa/cultural com humor, proporcionando o desenvolvimento do trabalho intercultural em sala de aula, apesar de os autores não indicarem esse aspecto explicitamente. Nesse sentido, o docente não pode ser "refém do livro escolhido" (ROJO, 2013, p. 170). Ele deve ser autônomo, pesquisador ativo, para que possa complementar, aprofundar, refletir junto com os alunos, a partir de outras perspectivas.

No Domani 3, entre os temas culturais trabalhados estão: os números telefônicos de urgência, Sicília e Sardenha; as regiões italianas, Salento e Cilento; os italianos à mesa; o futebol na Itália, os esportes mais populares na Itália; as palavras estrangeiras no italiano, os erros mais comuns dos italianos; Pier Paolo Pasolini, história da língua italiana, os títulos honoríficos na Itália; o naufrágio do Costa Concórdia, estereótipos culturais; Giuseppe e Anita Garibaldi, história da unidade da Itália, etc.

$\mathrm{Na}$ oitava unidade, que inicia na página 63 , os autores iniciam com uma atividade de áudio, uma entrevista de 1968 com o escritor Pier Paolo Pasolini. Nessa entrevista, Pasolini fala sobre a unificação da Itália e o papel da língua italiana oficial nesse processo. Para exemplificar, citamos o seguinte trecho da entrevista, da primeira fala de Pasolini:

\footnotetext{
${ }^{14}$ In Italia non c'è un'unica cucina nazionale ma sono presenti tante cucine delle regioni e delle città, com piatti tipici molto famosi. Alcuni piatti popolari: le trofie al pesto a Genova, il risotto a Milano, i tortellini a Bologna, la ribollita a Firenze, gli spaghetti alla carbonara a Roma, le orecchiette in Puglia, la pasta alla Norma in Sicilia, il maialino in Sardegna (GUASTALLA; NADDEO, 2011a, p.60).
} 
[...] O italiano foi, praticamente, uma língua somente literária por muitos séculos, ou seja, até praticamente há dez ou vinte anos. E esse prestígio literário nasceu em Florença, em uma situação histórica, naturalmente, muito diferente da atual. Os três grandes pais do italiano, ou seja, Dante, Petrarca e Boccaccio, foram impostos para o resto da população italiana por razões de prestígio literário (GUASTALLA; NADDEO, 2012b, p.51, tradução nossa). ${ }^{15}$

Nesse sentido, percebe-se que há uma preocupação do livro didático em explicar o motivo pelo qual o italiano oficial tem prestígio, preocupando-se com o desenvolvimento da competência sociolinguística.

Na sequência da entrevista, Pasolini fala sobre o desenvolvimento do italiano regional e individual e o jornalista retruca: "Ma... vicino l'italiano poi ci sono anche $i$ dialetti veri e propri" (Mas... próximo ao italiano há também os dialetos verdadeiros e próprios) e Pasoline responde: "Certo. Che sono delle lingue potenziali che non sono arrivate al grado di lingua perché sono state soppiantate dal prestigio letterario del fiorentino" (Certamente. São línguas potenciais que não chegaram ao nível de língua por terem ficado abaixo do prestígio literário do fiorentino), o que demonstra, mais uma vez, um discurso referente ao desenvolvimento da consciência sociolinguística. Pasolini discorre, ainda, sobre o fato de há quinze, vinte, trinta anos, o italiano não ser verdadeiramente unitário e que o italiano oficial não é mais literário (de Florença), mas sim técnico e tecnológico (de Milão).

Para finalizar, o jornalista questiona se Pasolini considera melhor essa hegemonia tecnológica sobre a língua do que aquela literária, ao passo que o entrevistado responde: “[...] Non è né migliore né peggiore [...]" (Não é nem melhor nem pior). O discurso demonstra, novamente, o respeito à diversidade linguística e a compreensão de que a oficialização de uma variedade é concretizada por fatores políticos e econômicos da comunidade e da sociedade.

Na sequência da unidade, Guastalla e Naddeo (2012b, p.64-65) pedem para que o estudante complete a cronologia da língua italiana com as três informações da lista sobre uma linha do tempo. Nessa cronologia os autores apresentam a origem da língua italiana, sendo o latim falado; a chegada de novos povos e as línguas neolatinas e a o latim como língua administrativa e escolar; o fato de Dante Alighieri, Petrarca e Boccaccio terem escrito suas obras em dialeto florentino (de Florença); a imposição do dialeto florentino como língua

\footnotetext{
15 [...] L'italiano praticamente è una lingua soltanto letteraria per molti secoli, cioè fino praticamente a dieci o vent'anni fa. E questo prestigio letterario è nato a Firenze in una situazione storica naturalmente molto diversa dall'attuale. I tre grandi padri dell'italiano, cioè Dante, Petrarca e Boccaccio si sono imposti al resto della popolazione italiana per ragioni di prestigio letterario (GUASTALLA; NADDEO, 2012b, p.51).
} 
unitária, com o passar do tempo; a unificação da Itália; o fim da Segunda Guerra Mundial e a língua italiana como código linguístico popularizado pelas mídias.

Ainda na página 65, Guastalla e Naddeo (2012b) apresentam um texto, no exercício $2 b$, em que se pede para que se complete com expressões apresentadas anteriormente, na atividade 2a. O que chama atenção, porém, é o conteúdo do texto, em que o autor faz uma reflexão sobre a formalidade da língua italiana, ou seja, sobre a variação de registro.

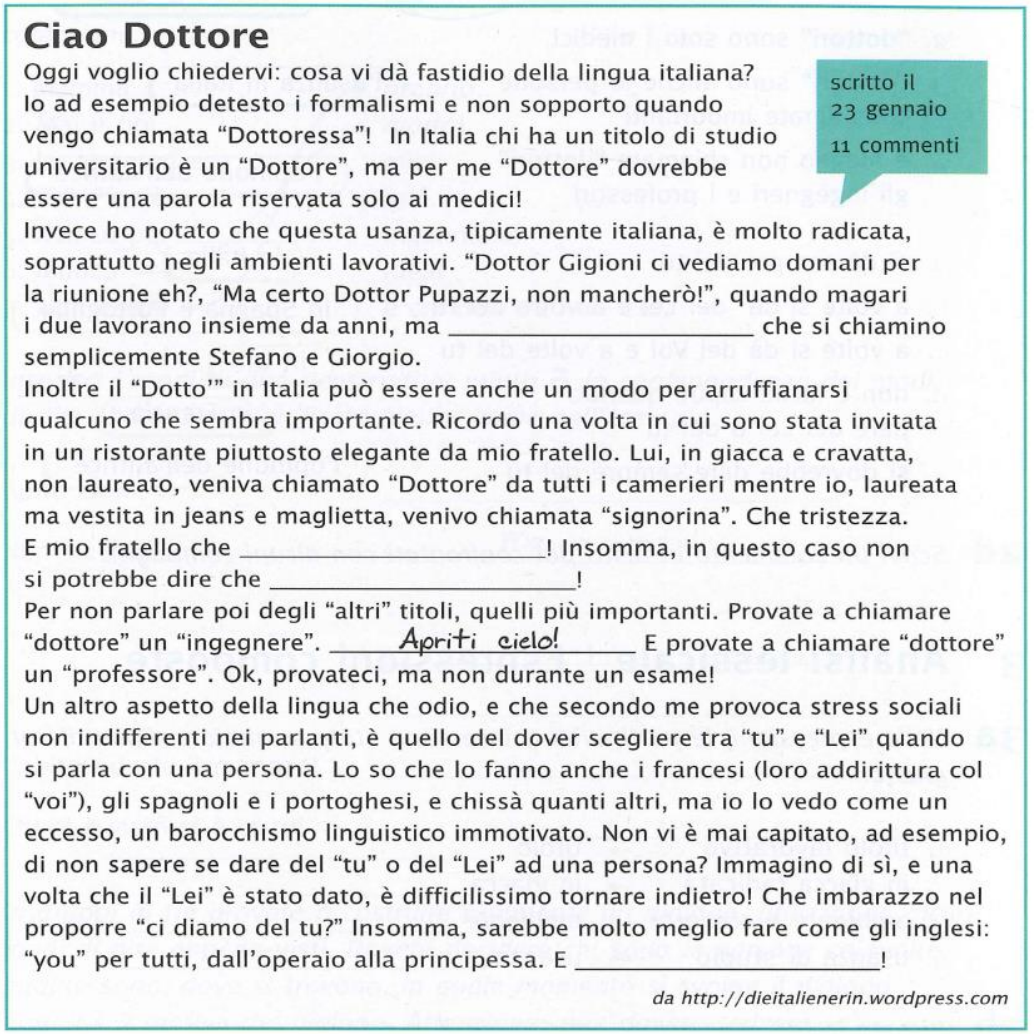

Figura 1 - Atividade $2 b$

Fonte: Guastalla e Naddeo (2012b, p. 65)

A variação de registro está relacionada à variação padrão e não padrão, em que o grau de formalidade de uma situação comunicativa definirá o registro a ser adotado, se será a norma culta ou uma popular. Assim, em "[....] contextos socioculturais que exigem maior formalidade, usamos uma linguagem mais cuidada e elaborada - o registro formal; em situações familiares e informais, usamos uma linguagem coloquial - o registro informal" (GÖRSK; COELHO, 2009, p. 77). Nesse sentido, Fishman (1974), com base na Sociologia da Linguagem, defende que as mudanças na língua ocorrem dependendo da situação:

Os membros de complexos sociais que compartilham um repertório linguístico devem saber (e sabem) quando mudar de uma variedade para outra. Uma categoria dessas mudanças é a conhecida como mudanças situacionais. Uma mudança de situação pode exigir uma mudança na variedade linguística (FISHMAN, 1974, p. 29). 
Fishman (1974) observa, ainda, que as mudanças em uma língua decorrem de mudanças de situações. A língua se coloca, no interior dos estudos sociolinguísticos, como heterogênea, marcada pelas relações entre língua e sociedade.

Na unidade 15 do Domani 3, há a preocupação com o desenvolvimento da consciência intercultural, ainda que seja a favor da cultura italiana. Com o título Una tragedia italiana (Uma tragédia italiana), os autores do livro didático apresentam o naufrágio do Costa Concórdia, que ocorreu em 2012, e sobre as polêmicas relacionadas, principalmente pelo fato de o incidente ter sido responsabilidade de um comandante italiano.

Na sequência, os autores apresentam atividades de interpretação do texto do ponto 1a e de outro texto em áudio, assim como exercícios de gramática (no caso, pontuação), entre outras atividades, até chegar ao quinto exercício, o qual tem relação com a análise proposta para este estudo, uma vez que reflete sobre os estereótipos em relação aos estrangeiros:

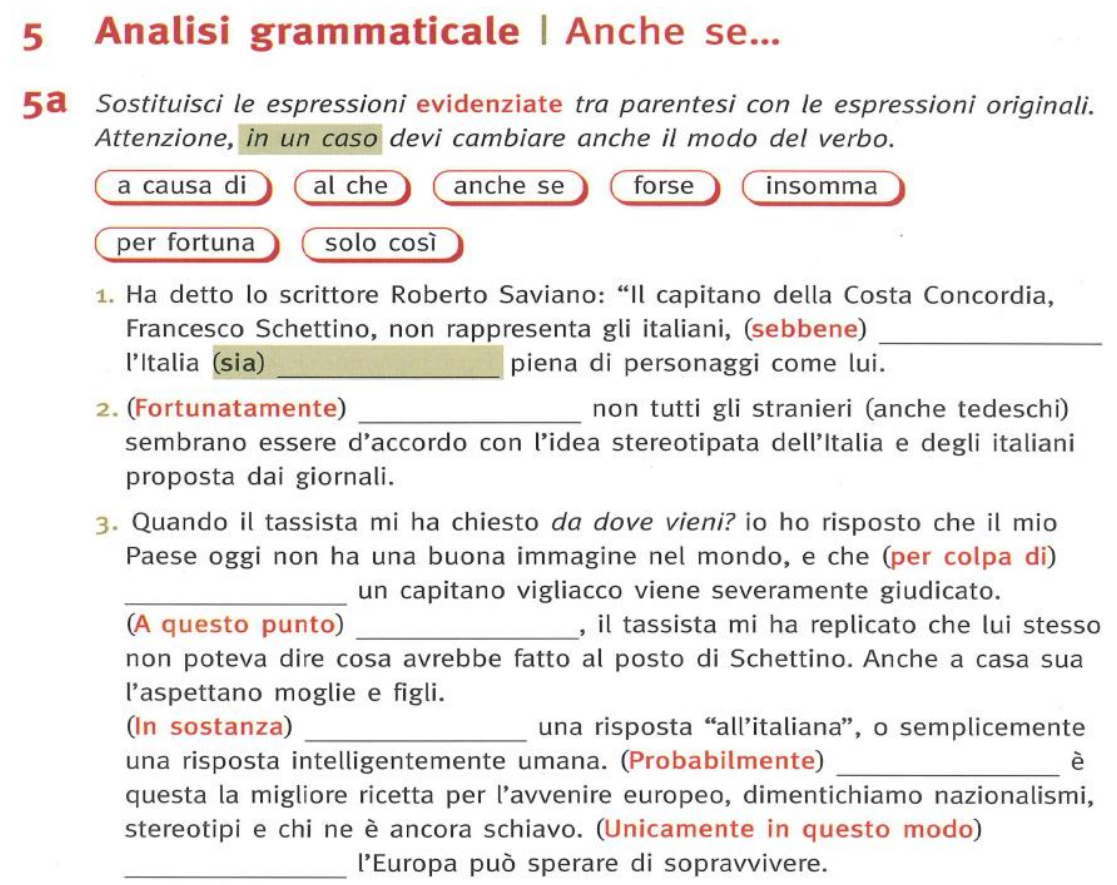

Figura 2 - Atividade 5a

Fonte: Guastalla e Naddeo (2012b, p. 128)

Nos pontos 1 e 2 do exercício acima, os discursos apresentados, tais como: "O capitão do Costa Concórdia, Francesco Schettino, não representa os italianos" e "Por sorte nem todos os estrangeiros (inclusive os alemães) parecem concordar com a ideia estereotipada da Itália e dos italianos apresentada pelos jornais", preocupam-se com a competência intercultural, principalmente no seguinte exercício 6 , com as seguintes perguntas para guiar a conversação: 
Se você não pertencesse à cultura a qual pertence, a qual cultura você se sentiria pertencente? Por quê? Há aspectos da sua cultura as quais você se sente orgulhoso? Há aspectos da sua cultura as quais você não goste? Há culturas as quais você imagine ser difícil integrar-se? Você já se deparou com alguma incompreensão cultural, sendo o centro dessa situação? (GUASTALLA; NADDEO, 2012b, p. 128, tradução nossa).

As perguntas acima demonstram o fato de todas as culturas terem pontos positivos e negativos e tem como intuito o desenvolvimento da competência intercultural. No entanto, ao apresentarem a polêmica em relação ao comandante italiano e ao utilizarem essa abordagem, nota-se que é conveniente para convencer e justificar que os italianos não podem ser representados por ele, em defesa da pátria italiana e da italianidade. Não teria, talvez, esse sentido, se o comandante fosse de outra nacionalidade.

O livro Magari também se define como um curso de "forte taglio culturale" (forte valor cultural), por apresentar cinco macro áreas temáticas (geografia, sociedade, artes, língua, história). Dividido em 21 unidades, o material didático apresenta diversos pontos de vista, a história passada e recente, fenômenos sócio-culturais e tendências e os estilos de vida emergentes na Itália. No sumário do material, os autores apresentam na primeira coluna o título/tema da unidade, na segunda coluna a gramática e o léxico, na terceira coluna os textos escritos e em áudio e na última os temas culturais. Como o objetivo deste trabalho é analisar a abordagem intercultural e o trabalho com as variedades linguísticas, apresentamos aqui apenas a primeira e a última coluna, ou seja, o título/tema da unidade e os temas culturais:

Tabela 1 - Título e temas culturais conforme o sumário do Magari

\begin{tabular}{|l|l|}
\hline \multicolumn{1}{|c|}{ Unità } & \\
\hline I.GEOGRAFIA & - il sistema dei trasporti in Italia \\
Luoghi d'Italia & - geografia fisica e politica d'Italia \\
& - monumenti e specialità culinarie \\
\hline 2.ARTI & l'arte italiana classica e contemporanea \\
Classico e moderno & - musei e luoghi d'arte in Italia \\
\hline 3.SOCIETÀ & - l'emigrazione italiana nel cinema \\
Emigrazione ed & - l'emigrazione italiana (1860-1970) \\
immigrazione & - l'immigrazione in Italia \\
& - personaggi: Sacco e Vanzetti, Mc Talibe \\
\hline 4.STORIA & - la fine del sistema dei partiti in Italia \\
Tangentopoli & - i partiti: prima e seconda repubblica \\
& - personaggi: Bettino Craxi, Sergio Cusani, Antonio Di Pietro \\
\hline 5.SOCIETÀ & - la casa in Italia \\
Casa & - l'arredamento \\
& - il design italiano \\
& - personaggi: Marco Lodoli \\
\hline 6.ARTI & - provocazioni dell'arte contemporanea \\
Arte contemporanea & - breve storia dell'arte italiana \\
& - personaggi: Antonio Tabucchi, Maurizio \\
\hline 7.SOCIETÀ & Cattelan \\
Psicologia & - gli italiani e lo psicologo \\
\hline
\end{tabular}


RELACult - Revista Latino-Americana de Estudos em Cultura e Sociedade

\begin{tabular}{|c|c|}
\hline $\begin{array}{l}\text { 8.LINGUA } \\
\text { Maschio - Femmina }\end{array}$ & $\begin{array}{l}\text { - donne italiane e lavoro } \\
\text { - sessismo della língua italiana } \\
\text { - personaggi: Dacia Maraini, Niccolò } \\
\text { Ammaniti, Italo Calvino, Susanna Tamaro }\end{array}$ \\
\hline $\begin{array}{l}\text { 9.STORIA } \\
\text { L'era Berlusconi }\end{array}$ & $\begin{array}{l}\text { - l'Italia negli anni di Berluconi } \\
\text { - personaggi: Silvio Berlusconi, Alexander Stille, Umberto Eco }\end{array}$ \\
\hline $\begin{array}{lc}10 . & \text { ARTI } \\
\text { Giallo italiano }\end{array}$ & $\begin{array}{l}\text { - la fortuna del genere giallo nella letteratura } \\
\text { italiana } \\
\text { - creare suspense } \\
\text { - personaggi: Massimo Carlotto, Giorgio Faletti, Carlo Lucarelli }\end{array}$ \\
\hline $\begin{array}{l}\text { 11. GEOGRAFIA } \\
\text { Mari e monti }\end{array}$ & $\begin{array}{l}\text { - vivere la montagna } \\
\text { - le isole Eolie } \\
\text { - geografia e cucina italiane } \\
\text { - personaggi: Mauro Corona }\end{array}$ \\
\hline $\begin{array}{l}\text { 12. SOCIETÀ } \\
\text { Periferia e architettura }\end{array}$ & $\begin{array}{l}\text { - il concetto di periferia } \\
\text { - i progetti architettonici di Roma } \\
\text { - Pisa tra passato e futuro } \\
\text { - l'architettura contemporanea in Italia } \\
\text { - personaggi: Dante Oscar Benini, Nanni Moretti }\end{array}$ \\
\hline $\begin{array}{l}\text { 13. ARTI } \\
\text { Cinema }\end{array}$ & $\begin{array}{l}\text { - storia del cinema italiano dal Neorealismo ad oggi } \\
\text { - } \text { i volti più rappresentativi del cinema italiano } \\
\text { - personaggi: Vincenzo Mollica, Mario Monicelli, Carlo Verdone, Sergio Leone }\end{array}$ \\
\hline $\begin{array}{l}\text { 14. STORIA } \\
\text { Cosa nostra }\end{array}$ & $\begin{array}{l}\text { - il fenomeno della mafia: origine, organizzazione, struttura e cronologia degli avvenimenti } \\
\text { - personaggi: Peppino Impastato, Leonardo Sciascia }\end{array}$ \\
\hline $\begin{array}{l}\text { 15. LINGUA } \\
\text { Non solo parolacce }\end{array}$ & $\begin{array}{l}\text { - la parolaccia, l'imprecazione e la bestemmia: aspetti culturali, sociolinguistici e giuridici } \\
\text { - il cinema italiano e la parolaccia }\end{array}$ \\
\hline $\begin{array}{l}\text { 16. SOCIETÀ } \\
\text { Vita d'ufficio }\end{array}$ & $\begin{array}{l}\text { - vestirsi e comportarsi sul posto di lavoro in Italia } \\
\text { - l'amore in ufficio } \\
\text { - il colloquio di lavoro } \\
\text { - personaggi: Stefano Benni }\end{array}$ \\
\hline $\begin{array}{l}\text { 17. ARTI } \\
\text { Scrittori }\end{array}$ & $\begin{array}{l}\text { - italiani lettori pigri } \\
\text { - personaggi: Valeria Parrella, Alessandro } \\
\text { Baricco, Italo Calvino } \\
\text { - letteratura italiana in pillole }\end{array}$ \\
\hline $\begin{array}{l}\text { 18. LINGUA } \\
\text { Mode e tic verbali }\end{array}$ & $\begin{array}{l}\text { - mode verbali } \\
\text { - le } 10 \text { espressioni più odiate dagli italiani } \\
\text { - il burocratese } \\
\text { - personaggi: Pietro Citati, Ritanna Armeni e } \\
\text { Giuliano Ferrara }\end{array}$ \\
\hline $\begin{array}{l}\text { 19. ARTI } \\
\text { Comicità }\end{array}$ & $\begin{array}{l}\text { - giochi di parole e doppi sensi } \\
\text { - la comicità e la satira } \\
\text { - le barzellette } \\
\text { - il teatro comico e la Commedia dell'arte } \\
\text { - personaggi: Stefano Benni, Alessandro Bergonzoni, Daniele Luttazzi, Dario Fo }\end{array}$ \\
\hline $\begin{array}{l}\text { 20. STORIA } \\
\text { Il fascismo }\end{array}$ & $\begin{array}{l}\text { - origini, sviluppo e crollo del regime fascista } \\
\text { - le parole del fascismo } \\
\text { - breve storia d'Italia dal fascismo a oggi } \\
\text { - il fascismo e l'arte } \\
\text { - personaggi: Benito Mussolini, Giacomo Matteotti, Filippo T. Marinetti }\end{array}$ \\
\hline $\begin{array}{lr}21 . & \text { LINGUA } \\
\text { Lingua e dialetti }\end{array}$ & $\begin{array}{l}\text { - tradizioni: la pizzica e la taranta } \\
\text { - breve storia della lingua italiana } \\
\text { - l'Italia, i dialetti e le lingue minori } \\
\text { - personaggi: gli Arakne Mediterranea, Gian Luigi Beccaria }\end{array}$ \\
\hline
\end{tabular}

Deve-se considerar que cada unidade didática (UD), ou seja, cada sequência didática, é construída, com base em um tema cultural central, contando com atividade de introdução, textos escritos, atividades de áudio, jogos de produção oral, produções escritas e jogos. Nesse sentido, a composição das unidades segue a clássica estrutura da unidade didática: globalità $\rightarrow$ analisi $\rightarrow$ produzione, determinada por Balboni (2003, p. 120) da seguinte maneira: 
globalità $\rightarrow$ analisi $\rightarrow$ riflessione $\rightarrow$ sintesi. Percebe-se, também, que o Magari segue os objetivos da unidade didática exemplificados por Mezzadri:

\begin{abstract}
Entre os objetivos do processo de educação linguística e, portanto, da UD, estão incluídos, além daqueles tipicamente linguísticos relativos às habilidades primárias, à gramática ou ao léxico, etc., há também metas educativas ligadas aos aspectos culturais, paralinguísticos, extralinguísticos e sociolinguísticos, assim como aquelas relativas às habilidades de interação ou de elaboração de textos (MEZZADRI, 2003, p. 15 , tradução nossa). ${ }^{16}$
\end{abstract}

Além dessas metas educativas ligadas aos aspectos culturais, extralinguísticos e sociolinguísticos, portanto, no guia do professor do Magari, Guastalla e Naddeo (2009) explicitam que o material tem como objetivo fazer com que o estudante seja ativo, com base na colaboração entre pares, tendo a teoria de Vygotskij como base. Descreve-se, também, de forma breve e rápida, o papel intercultural do material: "Com o objetivo de guiar a elaboração de hipóteses (não se fala somente de hipóteses gramaticais, mas também de hipóteses sobre aspectos culturais ou interculturais [...])" (GUASTALLA; NADDEO, 2009, p. 8, tradução nossa). ${ }^{17}$

O aspecto intercultural pode ser percebido já na terceira unidade do livro, a qual tem como tema Emigração e Imigração. A visualização desse fato fica evidente na página 34, com o sexto exercício, em que se propõe uma atividade de escrita: "Você se lembra da história de uma avó ou de um avô? Escreva-a". Na atividade ao lado, número 7, propõe-se que os estudantes leiam as seguintes frases e discutam essa questão com um colega: "A cultura nasce do encontro, da diversidade e da contaminação", "Os imigrantes tiram o trabalho dos nossos filhos", "Aqui tem muitos estrangeiros: devemos enviá-los para casa e ajudá-los estando eles em suas casas"; “A maior parte dos criminosos são imigrantes”, entre outras frases.

Na sequência, na próxima página, os autores do Magari apresentam um texto de um DJ senegalês na Itália, que fala sobre o preconceito que ele enfrenta devido à própria nacionalidade e as dificuldades para conseguir alugar um local para morar, o que demonstra, mais uma vez, o viés intercultural do material didático.

Assim como o Domani, há em alguns momentos, a pergunta de como é na língua/cultura/país de origem do estudante o assunto/tema discutido. $\mathrm{Na}$ oitava unidade, em

\footnotetext{
${ }^{16}$ Tra gli obbiettivi del processo di educazione linguistica e quindi delle UD vanno inclusi, oltre a quelle prettamente linguistici relativi alle abilità primarie, alla grammatica o al lessico, ecc., anche mete educative legate ad aspetti culturali, paralinguistici, extralinguistici e sociolinguistici, così come quelle relative alle abilità di interazione o di elaborazione dei testi (MEZZADRI, 2003, p. 15).

17 "Al fine di guidare ad elaborare delle ipotesi (non si parla solo di ipotesi grammaticali, ma anche di ipotesi su aspetti culturali o interculturali [...])" (GUASTALLA; NADDEO, 2009, p. 8).
} 
que se discutem os nomes de profissões no gênero masculino e feminino, os autores apresentam no terceiro exercício o seguinte enunciado para a atividade oral: "Para você o italiano é uma língua 'machista'? E na tua língua, como é? Há exemplos de 'machismo linguístico'? Converse sobre isso em grupo com alguns colegas". ${ }^{18}$. Essa reflexão sobre a língua proporciona não apenas o conhecimento gramatical, mas muito mais do que isso, possibilita o conhecimento da cultura italiana além da superficialidade, o conhecimento da cultura por meio do discurso materializado na língua e na gramática. Além disso, as perguntas acima demonstram, também, o viés intercultural, quando convida o estudante a comparar a situação da língua italiana com a sua língua materna.

Em diversos momentos, em diferentes unidades do Magari, os autores trazem temas que possibilitam o contato dos estudantes com a língua italiana informal, com diversos tipos de expressões, registros e gêneros, como na unidade 15, a qual tem como temática Non solo parolacce (Não apenas xingamentos), e que abordará expressões vulgares.

$\mathrm{Na}$ atividade 1c, o diálogo presente na unidade apresenta xingamentos (pirla, stronzo, $z o z z a, c a z z o$ ) e na atividade 1e, os autores perguntam qual é a expressão vulgar tipicamente milanesa, que será, no caso, pirla, um termo utilizado em diversos dialetos da Lombardia, principalmente em Milão. Originalmente, o termo significa pião, mas depois passou a significar o órgão sexual masculino, o que demonstra, mais uma vez, um viés sociolinguístico, no caso, de evolução e variação linguística.

No diálogo, no entanto, há frases em variações linguísticas italianas que não são a língua oficial, tais como. Entre as frases, “de tu’ moje!" (di tua moglie, em italiano oficial/ da tua mulher, em português), etc. Não há um encaminhamento, no entanto, no material didático, que chame atenção do professor e dos alunos sobre as variações apresentadas.

Em diversos outros momentos, há a presença de textos literários, como na unidade 16, página 190 e 191, com um conto de Stefano Benni, o que demonstra a diversidade de gêneros e de variações linguísticas de registro no livro didático e possibilitam ao professor, atento, trabalhar e refletir sobre essas questões em sala de aula, mostrando aos alunos tais aspectos.

A última unidade do Magari, número 21, com o tema Lingua e dialetti, é a que mais chama atenção em relação ao trabalho com a variação linguística. Entre os temas culturais apresentados no sumário estão: tradições: a pizzica e a taranta; breve história da língua italiana; a Itália, os dialetos e as línguas menores; personagens: os Arakne Mediterranea, Gian Luigi Beccaria.

18 “Secondo te l'italiano è una lingua 'maschilista'? E nella tua lingua cosa succede? Ci sono esempi di 'maschilismo linguistico'? Parlane in gruppo con alcuni compagni”. 
A unidade inicia com o gênero música, no caso, a canção Pizzicarella mia, escrita e cantada em dialeto apuliense. Os autores apresentam nas páginas subsequentes a letra da canção em dialeto e a tradução para o italiano padrão, assim como uma descrição sobre a origem, as crenças populares e o significado da dança típica pizzica.

Na segunda atividade, de produção oral, Guastalla e Naddeo (2009) colocam as seguintes perguntas para motivar o diálogo em sala de aula: "Quais informações você tem sobre os dialetos italianos? Você conhece alguma expressão em dialeto? Há alguma experiência que você pode contar? Converse em grupo com alguns colegas" (tradução nossa ${ }^{19}$. Tal atividade vincula a questão da variedade linguística com a abordagem intercultural, com o intercâmbio cultural em sala de aula e com a teoria de Vygotskij, em que o estudante é ativo e se desenvolve com base na colaboração entre pares.

Nas páginas 252 e 253, os autores apresentam, ainda, uma entrevista escrita com o professor e linguista, Gian Luigi Beccaria. O texto, intitulado Lingua e dialetti (Língua e dialetos), é apresentado em forma de atividade, uma vez que os estudantes devem inserir as perguntas nas respostas do entrevistado. Na primeira resposta à entrevista, Beccaria deixa evidente o respeito aos dialetos italianos:

[...] Antes de tudo deve-se dizer que não é verdade que os dialetos sejam uma degradação do italiano. É verdade, ao contrário, que italiano e dialetos tem papéis sociolinguísticos diferentes: o primeiro é a língua da comunicação na República Italiana; os outros têm um uso mais limitado, de qualquer modo, limitam-se ao uso familiar (tradução nossa). ${ }^{20}$

Na sequência, o entrevistado responde que: "Do ponto de vista linguístico, os dialetos italianos e a língua nacional estão no mesmo nível: ambos têm a mesma 'nobre' origem, ou seja, o latim"21. A afirmação corrobora para a desconstrução da relação entre variação e erro. Tarallo (2005) explica que as variações, ou seja, as formas não padrão, são estigmatizadas:

As variantes de uma comunidade de fala encontram-se sempre em relação de concorrência: padrão vs. não-padrão; conservadoras vs. inovadoras; de prestígio vs. estigmatizadas. Em geral, a variante considerada padrão é, ao mesmo tempo, conservadora e aquela que goza do prestígio sociolinguístico na comunidade. As variantes inovadoras, por outro lado, são quase sempre não-padrão e estigmatizadas pelos membros da comunidade (TARALLO, 2005, p. 11-12).

\footnotetext{
19 "Che informazioni hai sui dialetti italiani? Conosci qualche espressione in dialetto? Hai fato qualche esperienza che puoi raccontare? Parlane um gruppo con alcuni compagni”.

${ }^{20}$ [...] Innanzitutto va detto che non è vero che i dialetti siano uma corruzione dell'italiano. È vero invece che italiano e dialetti hanno un diverso ruolo sociolinguistico: il primo è la lingua della comunicazione all'interno della Repubblica Italiana; $i$ secondi hanno un uso più limitato, in qualche caso si limitano all'uso familiare.

21 "Dal punto di vista linguistico i dialetti italiani e la lingua nazionale sono sullo stesso piano: entrambi hanno avuto la stessa 'nobile' origine, cioè il latino".
} 
A partir disso, é importante discutir em sala de aula o que diferencia as variedades linguísticas da língua padrão, também chamada de standard, sendo o fato de esta última gozar de prestígio entre os falantes e a sociedade.

Na entrevista é abordada, ainda, a questão de a Itália ser o país que tem o maior número de dialetos, proporcionalmente ao tamanho de sua superfície. Beccaria explica que isso se deve à história do país e à unificação política tardia. Para finalizar, o entrevistado esclarece que os dialetos italianos podem ser divididos em duas áreas principais, em que se poderia traçar uma linha que vai da La Spezia à Rimini. Assim, têm-se os dois grandes grupos de dialetos italianos: aqueles setentrionais e aqueles centro-meridionais e toscanos, o que será mais bem explicado posteriormente na unidade.

Ainda na última unidade do Magari, os autores trazem outras atividades que chamam atenção, como o quiz na página 259, em que há perguntas sobre a origem do italiano, sobre a divisão dos dialetos italianos, sobre outras línguas que são faladas na Itália, como o albanês e o grego, sobre a semelhança do ladino (falado em Alto Adige) com o francês, entre outras questões.

Na página 260 os autores do livro didático apresentam, ainda, um texto com diversas informações sobre a situação linguística na Itália, a qual pode ser confrontada com um mapa ao fim do livro, na contracapa (e que tem relação com a última resposta de Beccaria).

Os dialetos italianos, no entanto, são tratados de forma mais aprofundada apenas na última unidade do Magari. No entanto, observa-se que esse tipo de discussão é extremamente importante no início do percurso de ensino-aprendizagem de língua italiana, para que o aluno não construa a ilusão do monolinguísmo italiano. Além disso, percebe-se que há, ainda, a necessidade de o professor de italiano, no caso, cascavelense, instrumentalizar seus alunos para que eles compreendam a própria história e a própria variedade linguística que podem eventualmente carregar ou que se deparam em sala de aula (com os colegas italodescendentes que tiveram o talian como língua materna).

\section{Conclusão}

O professor, portanto, deve utilizar o livro didático apostando em suas contribuições na mediação da construção do conhecimento em sala de aula. Nesse sentido, o docente competente é aquele que vai além das limitações do LD, o qual tem caráter genérico e por isso não pode contemplar todas as especificidades de um determinado contexto. Sendo assim, é 
função do docente complementar, ajustar, aprofundar determinado conteúdo ou tema abordado no LD, assim como apresentar e relacionar assuntos que o livro não contemple, mas que sejam necessários para o desenvolvimento da formação intercultural, crítica e reflexiva.

Nesse sentido, assim como Rojo (2013) observa, o professor precisa estar atento para não "perder a voz, ficar subordinado a esses impressos, deixar de planejar um ensino adequado e favorável a seu alunado" (ROJO, 2013, p. 167). Para Cavalcanti (2013), o professor deve ser um leitor crítico, ter uma formação que propicie ser um cidadão responsável, ético e com sensibilidade em relação à diversidade e pluralidade cultural, social e linguística, além de ser sintonizado com o tempo em que está inserido e com os avanços tecnológicos.

É preciso compreender os fatores históricos, geográficos e sociais, os quais, consequentemente, delineiam as variedades linguísticas e a cultura de uma comunidade, no caso, a de italodescendentes em Cascavel. É necessário, ainda, entender como se configura o comportamento em relação à variedade minoritária italiana, o talian, e à cultura desse grupo, assim como as diferenças históricas e linguísticas da língua italiana como língua estrangeira (língua padrão) e as variedades linguísticas italianas distintas daquela ensinada na escola como língua oficial. Tudo isso pode contribuir para que os alunos compreendam, respeitem e valorizem as diversidades linguísticas, a própria cultura, assim como a do "outro" (cf. Beloni, 2016).

Bortoni-Ricardo (1993, p. 74), com base em Cook-Gumperz, chama atenção para o processo de se relacionar o conhecimento que o aluno já tem (o velho) com o novo: "A fim de aprender, os alunos devem usar o que já sabem de modo a conferir significado ao que a professora lhes apresenta". Assim, a autora aponta uma solução para que os professores consigam lidar com as diferenças linguísticas e para que se deixem de lado o "valor cultural bem arraigado, a noção de erro gramatical” (BORTONI-RICARDO, 1993, p. 77).

O aluno instrumentalizado, ou seja, tendo consciência da própria variedade linguística e cultura (assim como sobre a língua e cultura do outro) será um sujeito mais crítico e entenderá que essa diversidade deve ser respeitada.

\section{Referências}

BAKHTIN, Mikhail; VOLOCHINOV, Valentin Nikolaevich. Marxismo e Filosofia da Linguagem. 6. ed. São Paulo: Hucitec, 1992.

Estética da Criação Verbal. São Paulo: Martins Fontes, 2003. 
BALBONI, Paolo Ernesto. Tecniche didattiche per l'educazione linguistica. Torino: Utet, 2003.

BELONI, Wânia Cristiane. A língua italiana pela perspectiva intercultural: uma análise de materiais didáticos para um contexto de ensino. In: $4^{\circ}$ Cielli. Colóquio Internacional de Estudos Linguísticos e Literários. Maringá. 2016.

BORTONI-RICARDO, Stella Maris. Educação bidialetal - O que é? É possível? In: SEKI, Lucy. (Org.). Linguística indígena e educação na América Latina. Campinas: Unicamp, 1993. p. 71-88.

2008.

O professor pesquisador: introdução à pesquisa qualitativa. São Paulo: Parábola,

BRASIL. Secretaria de Educação Fundamental. Parâmetros Curriculares Nacionais: terceiro e quarto ciclos do ensino fundamental: língua estrangeira /Secretaria de Educação Fundamental. Brasília: MEC/SEF, 1998.

CAVALCANTI, Marilda C. Educação linguística na formação de professores de línguas: intercompreensão e práticas translíngues. In: MOITA LOPES, Luiz Paulo da. Linguística aplicada na modernidade recente. São Paulo: Parábola, 2013.

CALVET, Louis-Jean. Sociolinguística: uma introdução crítica. Trad. Marcos Marcionilo. São Paulo: Ed. Parábola, 2002.

CELENTIN, Paolo; SERRAGIOTTO, Graziano. Didattica dell'italiano in prospettiva interculturale. Venezia: Laboratorio Itals/Università Ca'Foscari, 2000. Disponível em: $<$ http://venus.unive.it/filim/materiali/accesso_gratuito/Filim_didattica_it_prospettiva.pdf >. Acesso em: 3 fev. 2016.

DE GIULI, Alessandro; GUASTALLA, Carlo; NADDEO, Ciro Massimo. Magari: corso di lingua e cultura italiana di livello intermedio e avanzato. Firenze: Alma, 2008.

FISHMAN, Joshua A. A sociologia da linguagem. In: FONSECA, Maria Stella V.; NEVES, Moema F. (Orgs.). Sociolingüística. Rio de Janeiro: Eldorado, 1974.

GIL, Antonio Carlos. Como elaborar projetos de pesquisa. 4. ed. São Paulo: Atlas, 2002.

GIMENEZ, Telma Nunes; FURTOSO, Viviane Bagio. Formação de professores de português para falantes de outras línguas: alguns apontamentos iniciais. In: CUNHA, Maria Jandyra Cavalcanti; SANTOS, Percília (Orgs.). Tópicos em Português Língua Estrangeira. Brasília: Universidade de Brasília, 2002.

GÖRSKI, Edair Maria; COELHO, Izete Lehmkuhl. Variação linguística e ensino de gramática. Working Papers em Lingüística, Florianópolis, ano 10, n. 1, p. 73-91, jan/jun. 2009.

GUASTALlA, Carlo; NADDEO, Ciro Massimo. Domani 1: corso di lingua e cultura italiana. Firenze: Alma, 2010a. 
$2010 \mathrm{~b}$

Domani 1: guida per l'insegnante. Corso di lingua e cultura italiana. Firenze: Alma,

Domani 2: corso di lingua e cultura italiana. Firenze: Alma, 2011a.

$2011 \mathrm{~b}$.

Domani 2: guida per l'insegnante. Corso di lingua e cultura italiana. Firenze: Alma,

Domani 3: corso di lingua e cultura italiana. Firenze: Alma, 2012a.

Domani 3: guida per l'insegnante. Corso di lingua e cultura italiana. Firenze: Alma, $2012 b$.

Magari: guida per l'insegnante. Firenze: Alma, 2009.

MELLO, Ana Catarina Moraes Ramos Nobre de; SANTOS, Danúsia Torres dos; ALMEIDA, Patricia Maria Campos de. Leitura em PLE: reflexões. In: CUNHA, Maria Jandyra Cavalcanti; SANTOS, Percília (Orgs.). Tópicos em Português Língua Estrangeira. Brasília: Universidade de Brasília, 2002.

MEZZADRI, Marco. I Ferri del mestiere. Perugia: Guerra, 2003.

MOITA LOPES, Luiz Paulo da. Uma linguística aplicada mestiça e ideológica: interrogando o campo como linguísta aplicado. In: MOITA LOPES, Luiz Paulo da (Org.). Por uma linguística aplicada INdisciplinar. São Paulo: Parábola, 2006, p. 13-42.

PARANÁ. Secretaria de Estado da Educação. Diretrizes Curriculares de Língua Estrangeira Moderna para os anos finais do Ensino Fundamental e para o Ensino Médio. Curitiba, 2008.

PELETEIRO, Aline Cristiane. Uma breve análise do material didático de língua italiana criado para o Centro de Estudo de Línguas da Secretaria de Educação do Estado de São Paulo. Revista Italiano UERJ, Rio de Janeiro, v. 5, n. 5, p. 233-247, 2014.

PENNYCOOK, Alastair. Uma linguística aplicada transgressiva. In: MOITA LOPES, Luiz Paulo da (Org.). Por uma linguística aplicada INdisciplinar. São Paulo: Parábola, 2006. p. 67-84.

PESSANHA, Eurize Caldas; DANIEL, Maria Emília Borges; MENEGAZZO, Maria Adélia. Da história das disciplinas escolares à história da cultura escolar: uma trajetória de pesquisa. Revista Brasileira de Educação, Rio de Janeiro, n. 27, p. 57-69, set./dez. 2004.

PICHIASSI, Mauro. Fondamenti di glotodidattica. Perugia: Guerra Edizioni Guru, 1999.

ROJO, Roxane. Materiais didáticos no ensino de línguas. In: MOITA LOPES, Luiz Paulo da. Linguística aplicada na modernidade recente. São Paulo: Parábola, 2013.

TARALLO, Fernando. (1990) A pesquisa sociolinguística. São Paulo: Ática, 2005. 